\title{
Application of the High Early Strength Type Expansive Agent to the Blast Furnace Slag Combination Concrete with GGBFS under Steam Curing
}

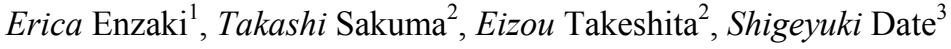 \\ ${ }^{1}$ Tokai University Master student \\ ${ }^{2}$ Taiheiyo Materials Corporation \\ ${ }^{3}$ Tokai University
}

\begin{abstract}
In recent years, the use of blast furnace slag material is being focused as environmental loading reduction and sustainable construction. However, in general, autogeneours shrinkage of the concrete using much amount of GGBFS is large in compared to normal concrete, therefore risk of cracking should be cared. On the other hand, strength development speed of concrete at early stage will be decreasing as the dosage of GGBFS increases, even under steam curing condition. It can be considered these points will be significant disadvantage in both productivity and quality of precast concrete. So in this study, early strength type expansive agent and setting accelerator were used in combination. As a result, it was confirmed that compressive strength at early stage is obviously increased. And steam curing temperature can be reduced about 10 degrees, and also, $600 \times 10-6$ of restraint expansion was obtained.
\end{abstract}

\section{Introduction}

Recently, use of blast furnace slag to the concrete in Japan is getting increased. This is because Green procurement and durability of concrete is being focused. This tendency is expected that it'll be increased increasingly from now on. In precast concrete production, it's necessary to make the temperature of the steam curing higher than usual, to ensure 2 cycle production. Because strength development speed of concrete at early stage will be decreasing as the dosage of GGBFS increases, even under steam curing condition. However, When the steam cure temperature set high, there is risk of a crack caused by internal constraint by temperature.
When using concrete which is blended blast furnace slag fine powder, especially replacing half of cement, and also compered with ordinary concrete, the risk of cracking increases. Because Portland blast furnace slag cement has a large autogeneous shrinkage [1-6]. On the other hand, the expansive agent of which high early strength is also developed in recent years [7-12]. So the purpose of this study is to improve both quality and productivity of GGBFS mixed concrete with steam curing by using expansive agent of which high early strength [13-19]. Furthermore, effect of the combined use of the setting accelerator was also investigated .

Table 1. Material Used

\section{Methods}

\begin{tabular}{|c|c|c|c|}
\hline Material & Type & Remarks & Symbol \\
\hline Cement & High-early-strength-portland cement & Density: $3.13 \mathrm{~g} / \mathrm{cm}^{3}$ & $\mathrm{C}$ \\
\hline \multirow{2}{*}{ Mineral Admixture } & Blastfurnace slagfine powder & Density: $2.90 \mathrm{~g} / \mathrm{cm}^{3} 4000$ blaine & $\mathrm{Sg}$ \\
\hline & Early-Strength type expansion material & Lime type Density:3.20g/ $\mathrm{cm}^{3}$ & EX \\
\hline Fine aggregate & Natural sand & Density in surface dried condition & S \\
\hline Coarse aggregate & Crushed stone & Density in surface dried condition & $\mathrm{G}$ \\
\hline Admixture & High-range water reducing agent & Polycarbonate type & Ad \\
\hline
\end{tabular}




\begin{tabular}{|l|l|l|l|}
\hline & Cure-accelerator & Inorganic nitrogen compounds & E \\
\hline
\end{tabular}

Table 2. Mix proportion

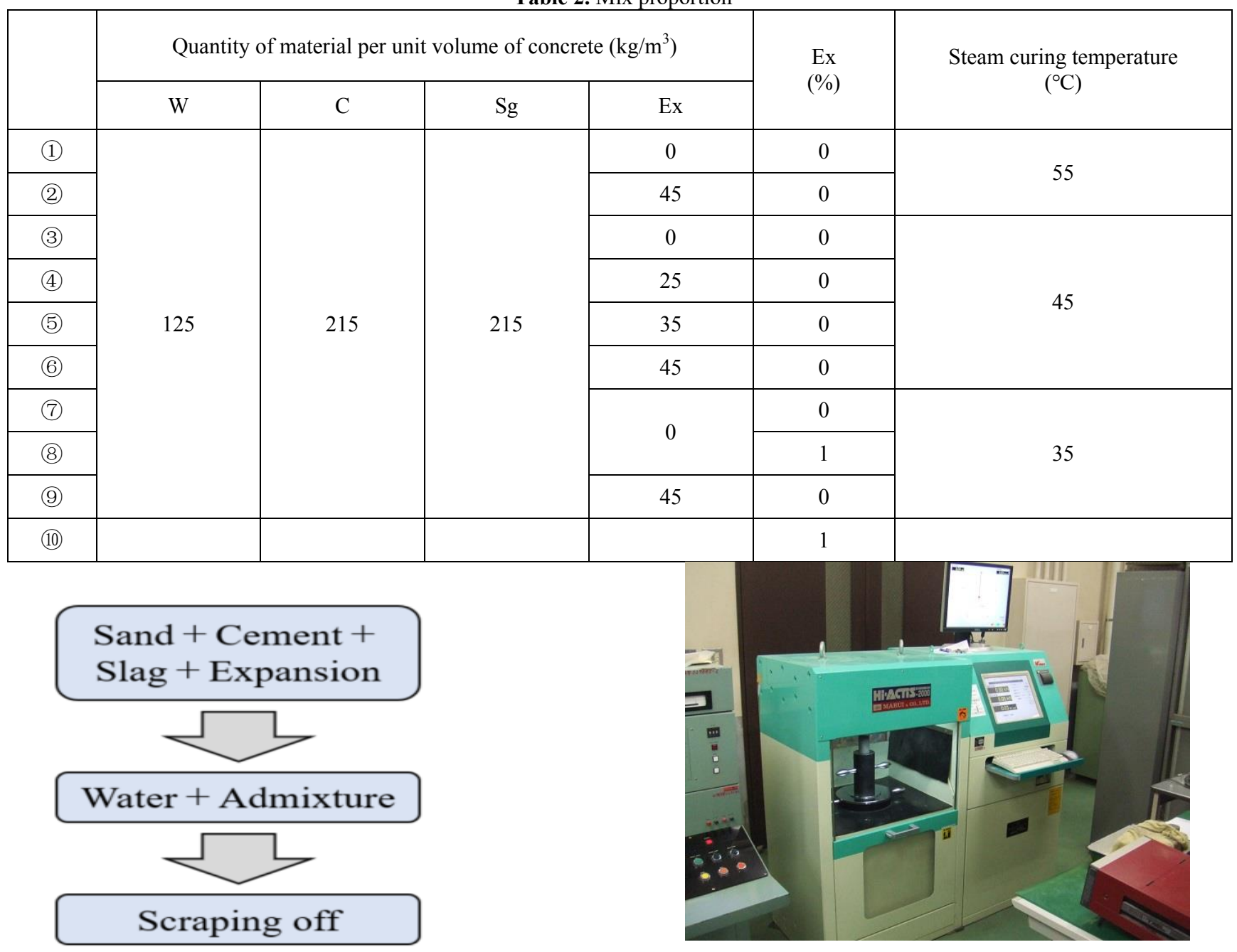

Photo 2. Compressive testing machines

The materials used is shown in Table 1, and the mixing and curing condition are shown in Table 2. Replacement ratio of blast furnace slag was 50\%. Expansive agent used was lime based material. The dosage of the water reducing agent was adjusted so that the slump was 3 $\pm 1.5 \mathrm{~cm}$. Using a $50 \ell$ pan type mixer(photo1), mix 30 seconds after solid material input, then the liquid material was added in 30 seconds and then mixed for another 90 seconds. All the specimen were cured in steam chamber for $5.5 \mathrm{~h}$ after $0.5 \mathrm{~h}$ precuring at ambient temperature, afterwards, was cooled to ambient temperature in $1 \mathrm{~h}$. Mixing procedure and curing condition were showed in Fig1 and Fig2. Concrete mixer is shown in Photo1. Compressive strength and restraint expansion were measured respectively. That's shown in photo2 and photo3. The compression strength was conducted according to JIS A 1108. The sample under test size was made $20 \mathrm{~cm}$ of $\phi 10$ and test material age were set to 7 hours and 14 days. Restraint expansion test was based on JIS A 6202. A restriction stick used was D13 of JIS G 3112. In the restraint expansion test, only the specimens of 8 and 10 in table 2 were used.

Photo 1. Mixer 


\section{Results and discussions}

\subsection{Compressive strength}

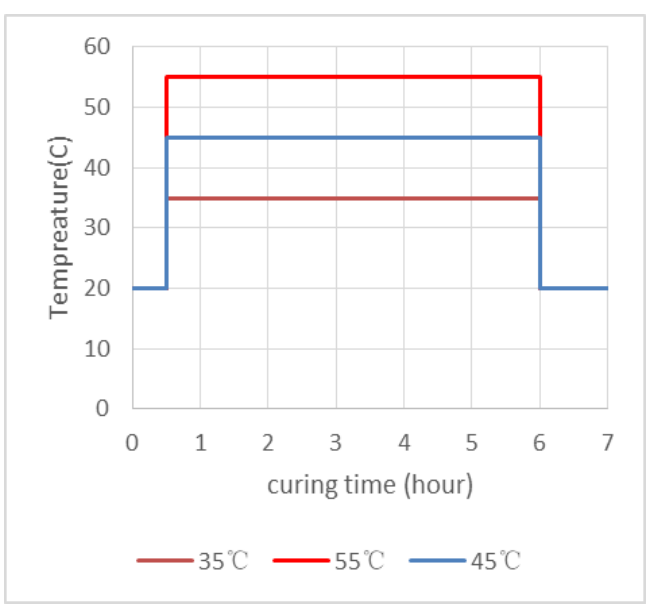

Figure 2. Curing condition

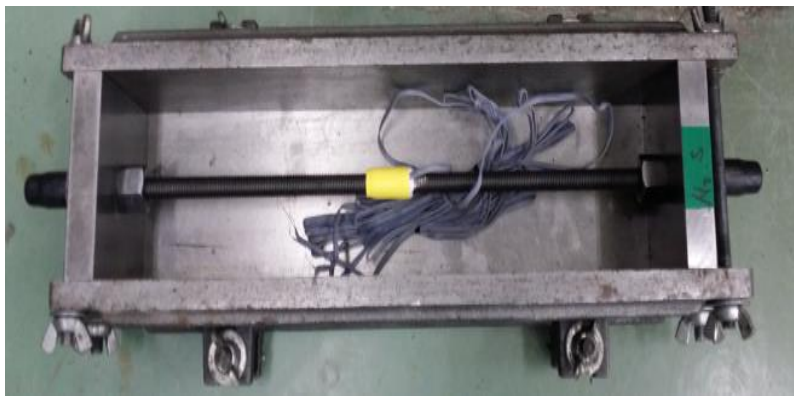

Photo 3. Restraint device

A relation between the compression strength and the steam curing temperature in the material age for 7 hours is indicated in figure-3. In the same mix proportions, it was confirmed that compressive strength increased as curing temperature increased. Focusing on the case which the steam curing temperature is $45^{\circ} \mathrm{C}$, compared with the control, when the expansive agent was added at $25 \mathrm{~kg} / \mathrm{m} 3$, compressive strength developed about 1.4 times. When added at $35 \mathrm{~kg} / \mathrm{m} 3$, developed about 1.5 times, when added $45 \mathrm{~kg} / \mathrm{m} 3$, about developed 1.7 times. So that, compressive strength tended to increase as the amount of expandable material increase. The steam curing temperature indicates the material age 7 hours in figure-4. Compressive strength of the control showed just only $5 \mathrm{~N} / \mathrm{mm} 2$, however, about 2.2 times of strength development was observed in the case when 3 added expansive agent $45 \mathrm{~kg} / \mathrm{m} 3$, about 1.7 times in the case when setting accelerator was added $1 \%$. When used in combination with setting accelerator, compressive strength was found to be up to 3.4 times at maximum. This is about the same strength as curing temperature of $55^{\circ} \mathrm{C}$, in the case of control. ( Figure-1) It was confirmed that the early strength enhancement effect by the combined use of the expansive agent and the setting accelerator. A relation between the compressive strength and the steam curing temperature in the material age for 14 days is indicated in figure-5. In the case of control, as the steam curing temperature increased, the compressive strength tended to decrease. When added expansion agent $45 \mathrm{~kg} / \mathrm{m} 3$, there was no strength degradation. When the expansive agent and the setting accelerator were used in combination, the compressive strength increased about 1.4 times as compared with control. Even at 14 days of age, effects by the expansive agent and the setting accelerator were confirmed. In consequence, it was confirmed that productivity of precast concrete can be expected to be improved by combined use of expansive agent and setting accelerator. Also when comparing 7 hour material age and 14 days material age, its confirmed that initial strength is more susceptible to temperature influence than long term strength.

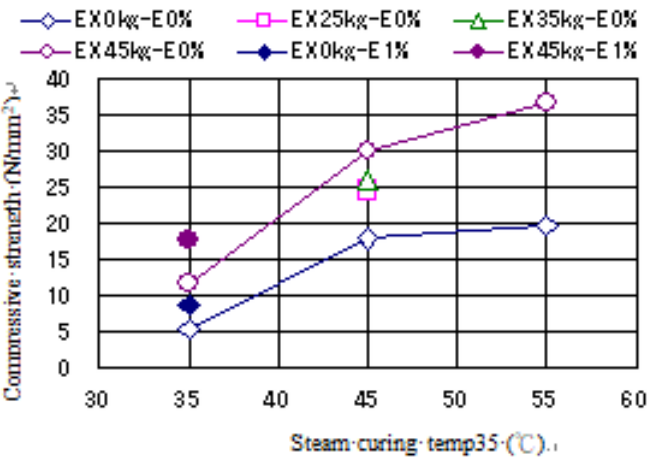

Figure 3. A relation between the compressive strength and the steam curing temperature in the material age for 7 hours.

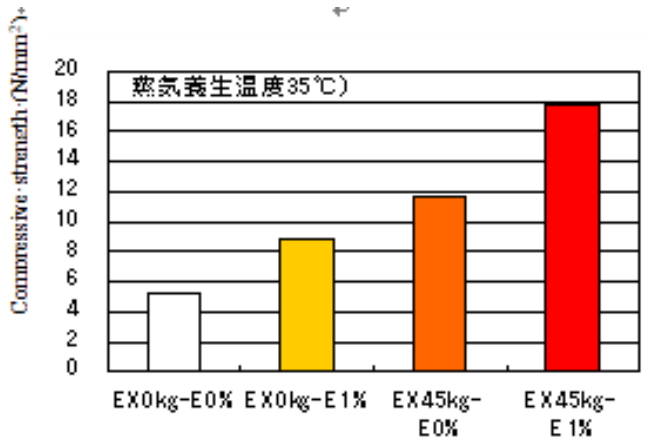

Figure 4. The steam cure temperature indicates the material age 7 hours compressive strength in each combination when being $35^{\circ} \mathrm{C}$.

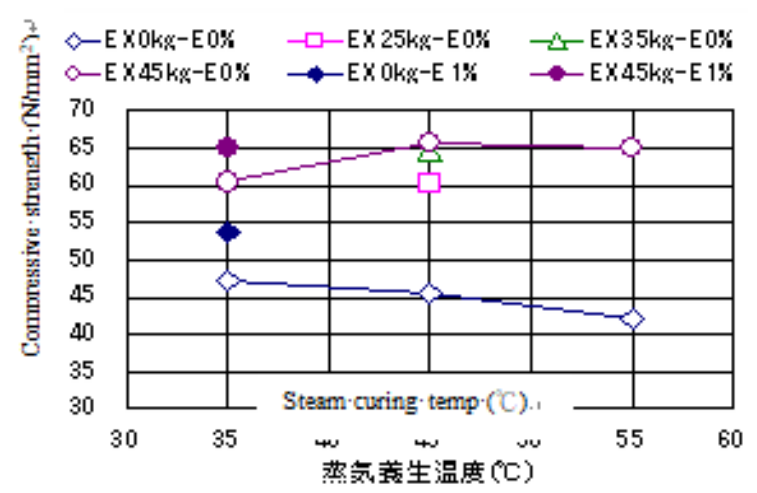

Figure 5. A relation between the compressive strength and the steam cure temperature in the material age for 14 days. 


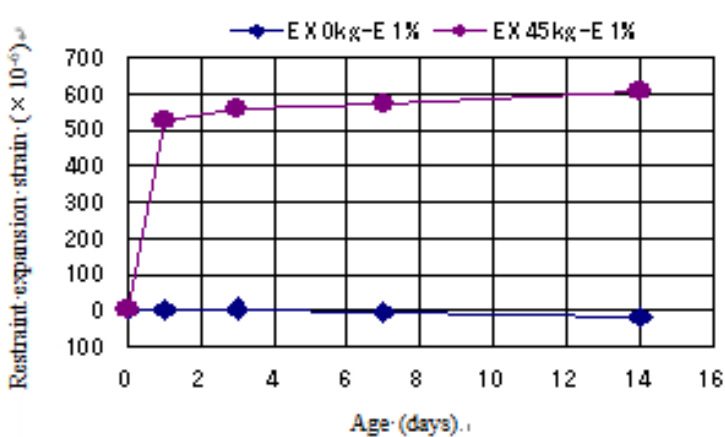

Figure 6. Change with time of restraint expansion strain.

\subsection{Restraint expansion rate}

A relation between restraint expansion strain and age is shown in Figure 6. By adding $45 \mathrm{~kg} / \mathrm{m} 3$ of expansive agent, expansion strain of about $600 \times 10-6$ was obtained at age of 14 days. It is considered that compressive prestress can be introduced into the concrete member. It can be inferred that temperature stress cracking and drying shrinkage cracking can be suppressed effectively. In addition, when applied to precast concrete products, cracking load can be increased and matrix becomes dene due to the chemical prestress effect, which is expected to improve durability.

\section{Conclusion}

In this study, effect of combined use of expansive agent and setting accelerator to concrete were confirmed as followings,

- Compressive strength at early stage was obviously increased.

- By addition of expansion agent and accelerator, concrete gain the same strength at $10^{\circ} \mathrm{C}$ lower steam curing comparing to concrete without accelerator and expansion agent.

- $600 \times 10^{-6}$ of restraint expansion could be introduced.

- Temperature doesn't affect long term strength .

- By increasing temperature, expansion agent become more effective.

As a future study, its should consider not only the initial strength but also long term strength for use as a concrete product, and also its should consider the best combination ratio, slag replacement ratio and expansion agent and, accelerator that will bring highest compressive strength.

\section{References}

1. Tomoya Miura Effect of blast furnace slag fine powder on self-shrinkage of concrete Vol.17,No.1,pp.359-364,1995

2. Ryou Niimura, Construction of precast concrete Concrete engineering 2 Each theory

3. Sonekazu Numada Utilization of blast furnace slag fine powder Concrete engineering annual paper Vol.25,No9,1987
4. Kenji Funamoto ,Atushi Sasahara, Heat generation and strength development characteristics of mass concrete using fly ash, Architectural Institute of Japan Structural system paper No.540,No1-6,2001

5. Toshiyuu Urano,Gaku Matsuda,Shunbun Hisano, On the Strength Characteristics and Salt Permeability of Precast Concrete Using Admixture of Fly Ash or Blast Furnace Slag Fine Powder,Cement Science and Concrete Technology,Vol.69

6. Yuuya Suda,Gou Saitou,Tatsuhiko Sahaku, Study on phase composition and compressive strength of various cemented hardeners, Cement Science and Concrete Technology,Vol.66,2002

7. Michio Takeuchi,Yuuji Sudou,Nikuo Watanabe, Effect of nitrite-based rust inhibitor on concrete specimens exposed to flying salt environment for 20 years, Concrete engineering annual paper,Vol.32,No1,2010

8. Manki Kawamura,Shin Tanigawa,Shunbun Kotou, Corrosion resistance of nitrous acid by reinforcing bars from the composition of pore solution of mortar, Concrete engineering annual paper,No.8.No.1,1997

9. Gakushi Iyoda,Yuusuke Ootsuka,Kouki Sagawa, Relation between curing condition and durability of concrete mixed with blast furnace slag fine powder

10. C.R.Cruz,M.Gillen Therminal expansion of portland cement paste,mortar and concrete at high temperature,June 1980

11. Santon,Thomas E,Expansion of Concrete thougth Reaction between Cement and Aggregate,December 1940,v66,pp1781-1811

12. Meyers, S L,Thermal Expansion Characteristics of Hardened cement paste and of concrete, Vol30,pp193-203,

13. Shingo,Miyazawa,Tsuyoshi Satou,Self-contraction stress of ultra high strength concrete by reinforcement restraint, Annual report on concrete engineering,Vol.15,No.1,pp57-62,1993

14. Eiichi Tazawa,Shingo Miyazawa, Influence of binder and compounding on autogenous shrinkage of cementitious materials, civil engineering Conference paper, No. 502, V-25, pp. 43-52, 1994

15. Mitsuru Tanimura, Hikoji Hyodo, Tatsuzo Sato, Ryoichi Sato:

Study on shrinkage reduction of high strength concrete, Annual Concrete Engineering paper, Vol.22,

16. Japan Concrete Engineering Association, Research Committee for Autistic Shrinkage

Subsidy report, pp. 195-198, 1996

17. Ding Hai Wen, Hiroaki Kono, Hiroshi Watanabe, Shuichi Sato:Research on linear expansion coefficient of high strength concrete, Annual Concrete Engineering paper, Vol.22, No.2, pp. 955960, 2000

18. Japan Concrete Engineering Association, Report of the Autonomous Shrinkage Research Committee, pp. 43-50, 1996

19. Megumi Yano, Fumiharu Nagahara, Junpei Hagihara, Tomoaki Hotta: Experimental Study on Autogenous Shrinkage of High Fluidity Concrete, Cement and Concrete Papers, No. 54, pp. 673 - 679, 2000 